Literature Review

\title{
Mycobacterium Abscessus Native Tricuspid Valve Endocarditis. Is a Six-Week Course of Combination Antibiotic Therapy Enough?
}

\author{
${ }^{1}$ Rabindra Ghimire, ${ }^{1}$ Dora Lebron, ${ }^{1}$ William Matthew Wooten, ${ }^{2}$ Niki Tyler Winters, \\ ${ }^{3}$ John M Cahill, ${ }^{1}$ Alicia Lagasca, ${ }^{1}$ Alexandra Stang and ${ }^{1}$ Paul Cook \\ ${ }^{I}$ Division of Infectious Diseases, East Carolina University at Brody School of Medicine, United States \\ ${ }^{2}$ Medical Student, East Carolina University at Brody School of Medicine, United States \\ ${ }^{3}$ Division of Cardiology, East Carolina University at Brody School of Medicine, United States
}

\author{
Article history \\ Received: 31-10-2019 \\ Revised: $17-12-2019$ \\ Accepted: 12-02-2020 \\ Corresponding Author: \\ Rabindra Ghimire \\ Clinical Assistant Professor, \\ Division of Infectious Diseases, \\ East Carolina University at \\ Brody School of Medicine, \\ United States \\ Email: drrabindraghimire@gmail.com
}

\begin{abstract}
A 24-year-old Caucasian woman with a history of intravenous drug abuse and multiple hospital admissions for substance abuse related medical problems presented with pneumonia and was discharged home on oral antibiotics. Three days later, her blood culture grew acid fast bacilli, which was subsequently identified as M. abscessus subspecies abscessus. Transthoracic and transesophageal echocardiogram (TTE and TEE respectively) was suggestive of tricuspid valve (TV) endocarditis. CT scan of the chest showed evidence of septic pulmonary emboli, pneumonic consolidation and pleural effusion requiring chest tube placement. BAL and blood cultures grew Mycobacterium abscessus while pleural fluid cultures remained sterile. She was treated with a combination antibiotic therapy and completed a six-week course with resolution of her symptoms and microbiological cure. We present this rare case of $M$. abscessus native tricuspid valve endocarditis associated with lung infection treated with a short course of combination antibiotic therapy.
\end{abstract}

Keywords: Mycobacterium abscessus, Endocarditis, Intravenous Drug Use, Combination Antibiotic Therapy

\section{Introduction}

Mycobacterium abscessus is a nontuberculous acidfast bacillus commonly found in water, soil, or dust. It is categorized as a rapidly growing mycobacterium (RGM) and is considered difficult to treat due to different mechanisms of antibiotic resistance (Huth et al., 2015; Mishra et al., 2015). It is commonly acquired through unsterile injections, invasive medical procedures that used contaminated equipment, or contaminated soil that enters an open wound (CDC, 2010). M. abscessus most commonly infects the skin and soft tissues or lungs. Although mycobacterial endocarditis is rare, it should be considered in a differential diagnosis when evaluating a septic patient with prosthetic cardiac devices, trauma, indwelling vascular access, a history of intravenous drug use, recent surgical procedures, or immunocompromised status (Huth et al., 2015; Bush et al., 2011; Rodge et al., 2017). Approximately $5-10 \%$ of all IE cases are rightsided endocarditis. Of those, about $90 \%$ involve the tricuspid valve (TV) and septic pulmonary emboli occur in about $5.7 \%$ of the patients (Song et al., 2016). TV endocarditis is strongly associated with intravenous drug use (Rodge et al., 2017). Infective endocarditis (IE) of the native heart valves due to $M$ abscessus has been reported in persons who inject drugs (PWID) and in persons with central venous catheters (Hussain et al., 2017; Liebeskind et al., 2001). Only one case thus far has been reported with survival beyond 4 months of completion of antibiotic therapy (Huth et al., 2015). 


\section{Case Report}

A 24-year-old Caucasian women with a history of intravenous drug use and multiple prior admissions to our hospital presented to the emergency department with intermittent fevers for 3-4 months. She was having chills, night sweats and productive cough without hemoptysis for the past 3 days. She acknowledged using cocaine and intravenous heroin every few days after being discharged from our hospital six months ago at which time she was treated with a 6 weeks course of intravenous antibiotics for methicillin resistant Staphylococcus aureus endocarditis (MRSA) of the tricuspid valve associated with septic pulmonary emboli. She also had a MRSA abscess in the right upper arm that required incision and drainage.

She was afebrile on presentation and had multiple track marks in her upper extremities. Chest examination demonstrated decreased breath sounds in the right infrascapular area with some crackles. Her white blood cell count (WBC) was $6900 / \mu \mathrm{L}$, hemoglobin was $10.9 \mathrm{gm} / \mathrm{dL}$ and platelets were $209,000 / \mu \mathrm{L}$. Her creatinine was 1.86 $\mathrm{mg} / \mathrm{dL}$ with an estimated GFR of $33 \mathrm{ml} / \mathrm{min}$. Human immunodeficiency virus (HIV) antigen and antibody test was negative. Chest radiograph demonstrated right lower lobe airspace disease suggestive of pneumonia. Patient was admitted for IV antibiotic therapy and hydration and received 3 days of IV ceftaroline. She remained afebrile and was discharged home on trimethoprim/sulfamethoxazole (TMP/SMX) and amoxicillin/clavulanate for presumed community acquired pneumonia. After she was discharged, growth of acid-fast bacilli (AFB) was reported from each aerobic bottle of 2 sets drawn on hospital day 1 and 2. A rapidly growing mycobacterial (RGM) infection was suspected and she was called to be admitted to the hospital. She was empirically treated with azithromycin, amikacin and imipenem. A transthoracic echocardiogram (TTE) demonstrated a freely mobile $7 \times 7 \mathrm{~mm}$ echodensity attached to the TV associated with mild tricuspid regurgitation directed towards the interatrial septum (Fig. 1). CT angiogram of the chest showed filling defects within several large right lower lobe pulmonary arteries, dense right lower lobe consolidation with trace pleural effusion and mediastinal and right hilar adenopathy (Fig. 2). The transesophageal echocardiogram demonstrated $15 \mathrm{~mm}$ vegetation in the TV with moderate tricuspid regurgitation. A CT chest performed 5 days after admission, due to worsening shortness of breath, showed progressive consolidative changes in the right lower lobe along with new consolidation in the right middle lobe and increasing mild to moderate right pleural effusion. Cardiothoracic surgical team was consulted for surgical recommendation.

The patient underwent bronchoscopy with bronchoalveolar lavage (BAL) and therapeutic thoracoscopy with drainage and thoracostomy tube placement on day 8 of hospitalization. Sero-sanguineous fluid was noted in the tube drain. Chest tube remained in place for $48 \mathrm{hr}$ and was removed without complication. BAL cultures were reported growing AFB as well. At this point, linezolid was added to the regimen. Multiple sets of blood cultures drawn during the hospital course were negative after starting combination antibiotic therapy. Pleural fluid AFB cultures remained negative. Drug susceptibilities were available 3 weeks later (performed at University of Texas Health Science Center in Tyler, TX). The isolate was reported susceptible to amikacin. Linezolid, imipenem and cefoxitin were reported to have intermediate activity and TMP/SMX, ciprofloxacin, moxifloxacin, doxycycline, minocycline and clarithromycin were reported resistant (Table 1).

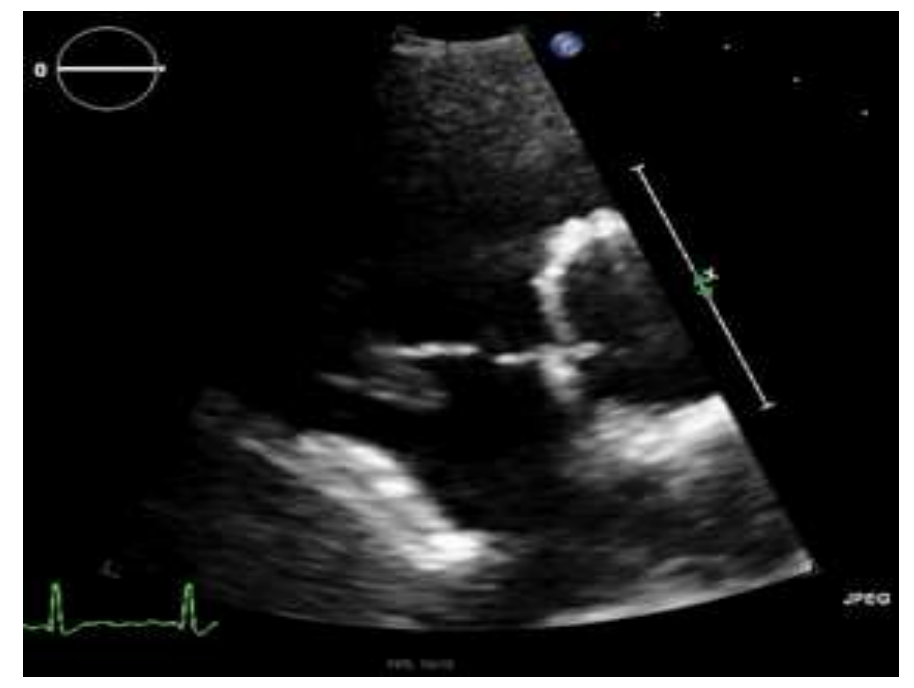

Fig. 1: Transthoracic echocardiogram ejection fraction $=60-65 \%$. There is trace mitral regurgitation. There is mild tricuspid regurgitation. Mobile echodensity on the tricuspid valve consistent with vegetation, measuring $1.5 \mathrm{~cm}$ 


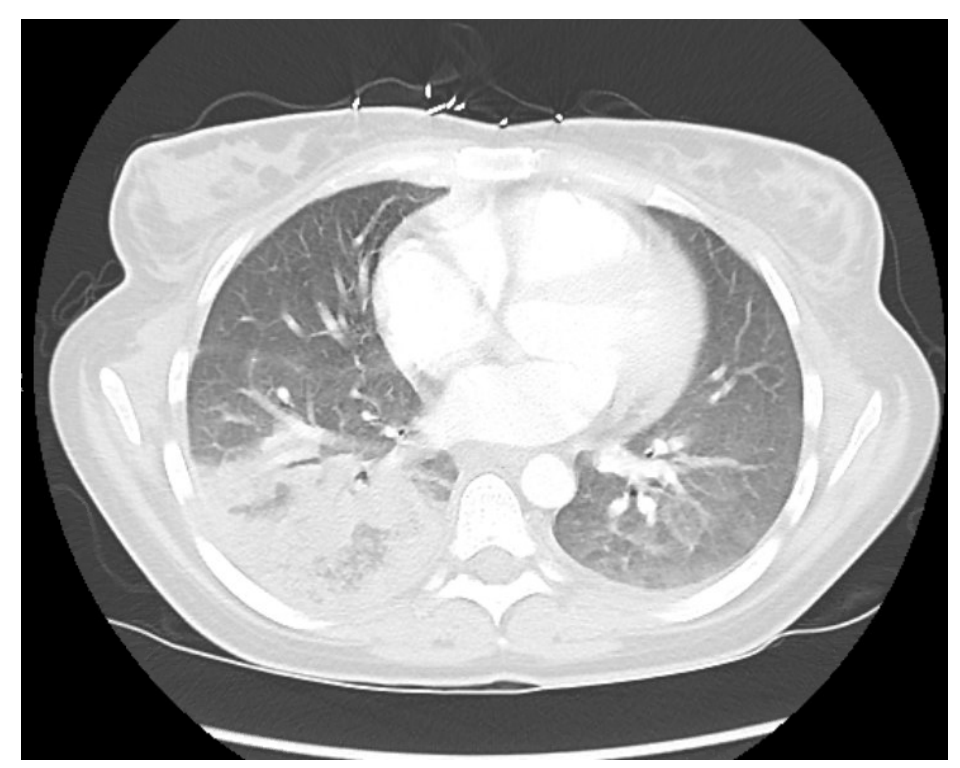

Fig. 2: 1st CTA Chest (Day 3) Low-density central filling defects within several right lower lobe pulmonary arteries consistent with persistent or recurrent pulmonary embolic disease with concomitant dense consolidation

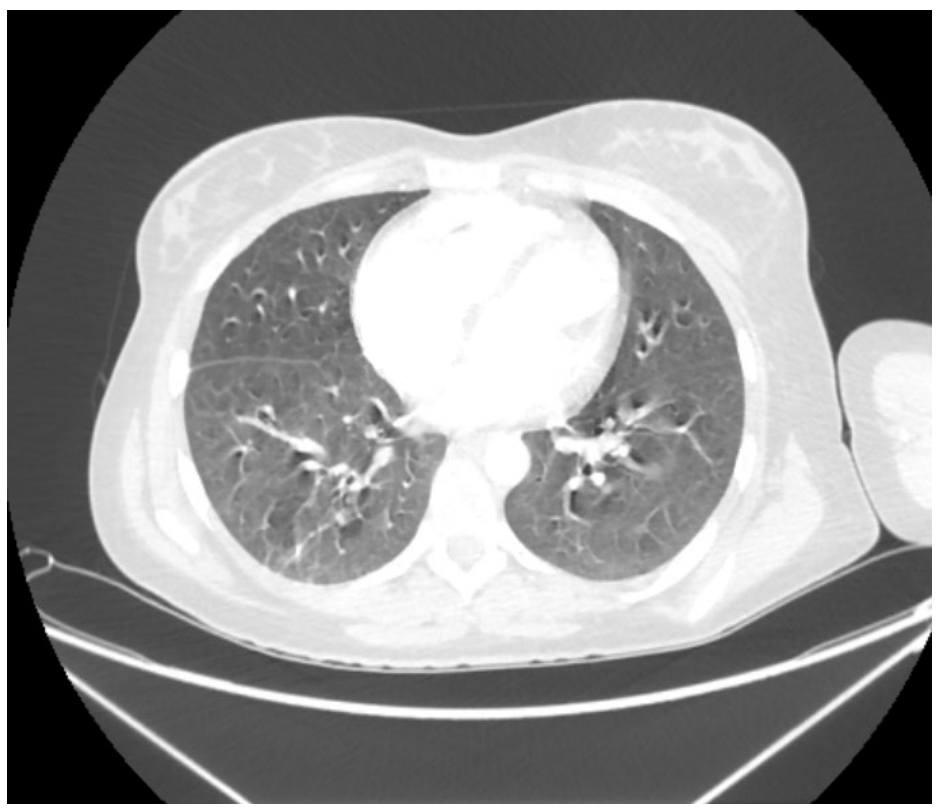

Fig. 3: Follow-up Chest CT Scan (1 year after completion of therapy and thoracostomy tube removal). The trachea and main bronchi are within normal limits. There is no evidence of a pneumothorax or pleural effusion. There is mild bibasilar subsegmental atelectasis. Otherwise, no focal airspace opacities are identified.

Inducible erm gene was noted to be present in the isolate and azithromycin and linezolid were discontinued and tigecycline was added to imipenem and amikacin. The patient continued to do well on combination therapy except for mild nausea requiring ondansetron as needed. The patient completed 6 weeks of antibiotics from the day of first negative blood culture (Table 2). When seen in the clinic 2 weeks after discharge, she had full resolution of her symptoms. A repeat TTE 1 month after completion of therapy demonstrated a decrease in size of tricuspid valve vegetation. Blood culture done 3 months later were sterile. A year later AFB blood cultures were done and remained negative and a repeat CT scan of the chest demonstrated resolution of pneumonia and effusion (Fig. 3). 
Table 1: Mycobacterium abscessus susceptibilities

\begin{tabular}{|c|c|c|c|c|}
\hline Antibiotic & Microdilution MIC $(\mu \mathrm{g} / \mathrm{mL})$ & $\mathrm{S}$ & I & $\mathrm{R}$ \\
\hline TMP/SMX & $4 / 76$ & & & $\sqrt{ }$ \\
\hline Linezolid & 16 & & $\sqrt{ }$ & \\
\hline Ciprofloxacin & $>4$ & & & $\sqrt{ }$ \\
\hline Imipenem & 8 & & $\sqrt{ }$ & \\
\hline Moxifloxacin & $>8$ & & & $\sqrt{ }$ \\
\hline Cefoxitin & 32 & & $\sqrt{ }$ & \\
\hline Amikacin & 8 & $\sqrt{ }$ & & \\
\hline Doxycycline & $>16$ & & & $\sqrt{ }$ \\
\hline Minocycline & $>8$ & & & $\sqrt{ }$ \\
\hline Tigecycline & 0.06 & & & - \\
\hline Tobramycin & - & & & - \\
\hline Clarithromycin & $>16$ & & & $\sqrt{ }$ \\
\hline Ertapenem & - & & & - \\
\hline Meropenem & - & & & - \\
\hline Clofazimine & 0.25 & & & \\
\hline
\end{tabular}

TMP-trimethoprim. S-susceptible, I-intermediate, R-resistant

Table 2: Antibiotic regimen used in current patient

\begin{tabular}{llc}
\hline Antibiotic used & Dose & Duration \\
\hline Azithromycin & $500 \mathrm{mg}$ daily & D1-D16 \\
Amikacin & $15 \mathrm{mg} / \mathrm{kg}$ daily to start and adjusted afterwards for trough $<4$ and peak of 50. & D1-D42 \\
Imipenem & $500 \mathrm{mg}$ Q6 hr & D1-D42 \\
Linezolid & $600 \mathrm{mg}$ Q12 $\mathrm{hr}$ & D9-D17 \\
Tigecycline & $100 \mathrm{mg}$ once and $50 \mathrm{mg} \mathrm{Q12} \mathrm{hr}$ & D17-D42 \\
\hline
\end{tabular}

$\mathrm{D}=$ days

\section{Discussion}

Bloodstream infections complicated by infective endocarditis due to unusual organisms such as Candida species and nontuberculous mycobacteria (NTM) are occasionally encountered in PWID. Disseminated RGM infection have been described in persons with underlying hematologic malignancies on chemotherapy, renal transplantation, autoimmune diseases and defects in interleukin-12 and interferongamma pathways (Redelman $\square$ Sidi and Sepkowitz, 2010). M. abscessus is one of about 20 human pathogen species of RGM and unusual cause of bloodstream infection and endocarditis in immunocompetent patients (El Helou et al., 2013). M. abscessus is known to produce biofilm and resist common disinfectants (Zambrano and Kolter, 2005). Municipal water supply systems could harbor this bacterium and can cause infection when contaminated water is used for intravenous injection (Zhang et al., 1997). We presume IV injection as the portal of entry in our case as the patient used tap water as a diluent.

Native valve endocarditis due to M. abscessus is rare. PubMed search using " $M$ abscessus endocarditis" revealed only a few cases of $M$ abscessus native valve endocarditis (Table 3), although several cases of bacteremia, prosthetic valve endocarditis and invasive infections associated with hospital outbreaks have been reported (Redelman $\square$ Sidi and Sepkowitz, 2010; El Helou et al., 2013; Baker et al., 2007; Richey et al.,
2013; Tsai et al., 2008). Use of IV drugs as a risk factor of $M$ abscessus endocarditis was documented by (Tsai et al. 2008; Garcia et al., 2014) and Huth et al. (2015). The presence of central or peripherally inserted catheters, hemodialysis catheters and coronary angiogram have also been described as the predisposing factors by others (Rodge et al., 2017; Williamson et al., 2009; Al-Benwan et al., 2010). Tricuspid and mitral valve involvement have been reported more often than the aortic valve. Although a male to female ratio of 1.38:1 of mycobacterial endocarditis was described by (Yuan, 2015), we found a male to female ratio of 3.5: 1 for native valve endocarditis due to $M$ abscessus.

Diagnosis of $M$ abscessus blood stream infection can usually be made from routine blood cultures in 3-4 days. A broth microdilution method is recommended for antimicrobial susceptibility testing by the National Committee for Clinical Laboratory Standards. MALDITOF MS is suggested to discriminate M. abscessus subspecies bolletii, abscessus and massiliense (Fangous et al., 2014). Macrolide resistance is rarely demonstrable at day 3 of incubation for this species. A minimum inhibitory concentration (MIC) read is recommended to be performed on day 14 of incubation and Erythromycin Ribosome Methyltransferase (ERM) gene sequencing can be done to detect an inducible erm gene. In our case, erm gene sequencing was performed at UTHSCT and revealed a functional erm gene indicating resistance to macrolides. We modified our antibiotic 
regimen accordingly. Erythromycin ribosome methyltransferase (ERM), aminoglycoside acetyltransferases, an aminoglycoside phosphotransferase, a rifamycin ADP-ribosyltransferase, a $\beta$-lactamase and a monooxygenase have been identified as responsible mechanisms for resistance of $M$. abscessus to different classes of antibiotics (Sfeir et al., 2018). Antimicrobial susceptibility testing of $M$ abscessus reported from Taiwan revealed susceptibility rate of $100 \%$ with tigecycline, $95 \%$ with amikacin, $92.5 \%$ with clarithromycin, $32.5 \%$ with cefoxitin, $22.5 \%$ with moxifloxacin, $12.5 \%$ with imipenem, $10 \%$ with ciprofloxacin, $7.5 \%$ with doxycycline and $7.5 \%$ with sulfamethoxazole (Huang et al., 2010). A recent report from the US showed similar susceptibility patterns with amikacin (93.8\%), clarithromycin (93.8\%), tigecycline $(89.1 \%)$, linezolid (44\%) and doxycycline (12\%) (Fangous et al., 2014). Imipenem MICs are not usually reported for M. abscessus due to lack of reproducibility (Brown-Elliott and Wallace, 2002). It may be appropriate to consider MICs and concentration rather than susceptible and resistant in selecting a drug. A drug with very high MICs in vitro is unlikely to be active in vivo whereas one just above a 'critical concentration' may have some activity, when combined with additive or synergistic agents (Haworth et al., 2017).

Table 3: Cases of Mabscessus native valve endocarditis

\begin{tabular}{|c|c|c|c|c|c|c|}
\hline $\begin{array}{l}\text { Author, } \\
\text { Year of } \\
\text { publication }\end{array}$ & $\begin{array}{l}\text { Patient's Age } \\
\text { (years)/Sex, } \\
\text { Country of } \\
\text { reporting }\end{array}$ & $\begin{array}{l}\text { Predisposing factors/ } \\
\text { Association } \\
\text { described }\end{array}$ & $\begin{array}{l}\text { Valve } \\
\text { involved }\end{array}$ & $\begin{array}{l}\text { Culture source/ } \\
\text { Confirmation }\end{array}$ & $\begin{array}{l}\text { Surgery or } \\
\text { Antimicrobial } \\
\text { therapy }\end{array}$ & Outcome \\
\hline $\begin{array}{l}\text { Liebeskind et al. } \\
\text { (2001) }\end{array}$ & 35/M, USA & Trip to El Salvador & Mitral & $\begin{array}{l}\text { Blood, bone } \\
\text { marrow and CSF. } \\
\text { Autopsy evidence } \\
\text { of endocarditis. }\end{array}$ & $\begin{array}{l}\text { IV ciprofloxacin, meropenem } \\
\text { and amikacin later switched } \\
\text { to clarithromycin and } \\
\text { imipenem. No surgery. }\end{array}$ & $\begin{array}{l}\text { Expired } \\
\text { on day } 69 .\end{array}$ \\
\hline $\begin{array}{l}\text { Corrales-Medina et al. } \\
\text { (2006) }\end{array}$ & 43/M, USA & $\begin{array}{l}\text { Construction worker, } \\
\text { colostomy }\end{array}$ & Aortic & $\begin{array}{l}\text { Blood, valve } \\
\text { culture }\end{array}$ & $\begin{array}{l}\text { Imipenem, linezolid and } \\
\text { clarithromycin } \rightarrow \text { AVR on } \\
\text { day } 50 \rightarrow \text { clarithromycin and } \\
\text { imipenem } \rightarrow \text { clarithromycin, } \\
\text { meropenem and amikacin. }\end{array}$ & $\begin{array}{l}\text { Expired } \\
\text { on day } 160 .\end{array}$ \\
\hline $\begin{array}{l}\text { Tsai et al. } \\
(2008)\end{array}$ & 29/M, Taiwan & IV heroin user & Tricuspid & Blood, sputum & $\begin{array}{l}\text { Multiple antibiotics from } \\
\text { June 2006- end. No surgery. }\end{array}$ & $\begin{array}{l}\text { Lost to } \\
\text { follow up. }\end{array}$ \\
\hline $\begin{array}{l}\text { Al-Benwan et al., } \\
(2010)\end{array}$ & 54/M, Kuwait & $\begin{array}{l}\text { Hemodialysis, } \\
\text { Chronic hepatitis } \\
\text { C, Perm catheter }\end{array}$ & Mitral & $\begin{array}{l}\text { Blood, perm } \\
\text { catheter tip }\end{array}$ & $\begin{array}{l}\text { Clarithromycin and tigecycline } \\
\rightarrow \text { clarithromycin held } \\
\text { and tigecycline monotherapy } \\
\text { used, non-compliant patient. } \\
\text { No surgery. }\end{array}$ & $\begin{array}{l}\text { Expired after } 5 \\
\text { weeks of } \\
\text { hospitalization. }\end{array}$ \\
\hline $\begin{array}{l}\text { Williamson et al. } \\
\text { (2009) }\end{array}$ & 29/F, USA & $\begin{array}{l}\text { Hemodialysis, } \\
\text { subclavian HD } \\
\text { catheter }\end{array}$ & Mitral & $\begin{array}{l}\text { Blood, subclavian } \\
\text { catheter culture }\end{array}$ & $\begin{array}{l}\text { Vancomycin } \rightarrow \text { After day } 10, \\
\text { HD catheter } \rightarrow \text { removed } \\
\text { vancomycin, piperacillin/ } \\
\text { tazobactam and gentamicin } \rightarrow \\
\text { after day } 20 \text { imipenem, } \\
\text { moxifloxacin and clarithromycin } \\
\text { initiated (when AFB stain } \\
\text { demonstrated AFB). No surgery. }\end{array}$ & $\begin{array}{l}\text { Expired after } 24 \\
\text { days of } M \\
\text { abscessus } \\
\text { therapy. }\end{array}$ \\
\hline $\begin{array}{l}\text { Garcia et al. } \\
\text { (2014) }\end{array}$ & 48/M, USA & IVDA & Mitral & $\begin{array}{l}\text { Blood, valve. } \\
\text { Coinfection } \\
\text { with Kocuria }\end{array}$ & $\begin{array}{l}\text { Vancomycin, ceftriaxone, } \\
\text { gentamicin } \rightarrow \text { imipenem, } \\
\text { amikacin and azithromycin. } \\
\text { MVR done. }\end{array}$ & $\begin{array}{l}\text { Expired } 4 \\
\text { months after } \\
\text { completion of } \\
\text { therapy due to } \\
\text { sepsis of unclear } \\
\text { etiology. }\end{array}$ \\
\hline Huth et al. (2015) & 52/M, USA & $\begin{array}{l}\text { Intravenous } \\
\text { drug use }\end{array}$ & Tricuspid & $\begin{array}{l}\text { Blood } \\
\text { Note: valve culture } \\
\text { negative. } \\
\text { Valve tissue: AFB } \\
\text { stain positive }\end{array}$ & $\begin{array}{l}\text { Cefoxitin, amikacin, } \\
\text { clarithromycin and moxifloxacin } \\
\rightarrow \text { tigecycline, linezolid, } \\
\text { clarithromycin and amikacin } \\
\rightarrow \text { day } 19 \text { linezolid discontinued, } \\
\text { added imipenem. Tricuspid } \\
\text { valvectomy on day } 41 \text {. } \\
\text { Tigecycline, amikacin, } \\
\text { imipenem and clarithromycin } \\
\text { continued till day } 77 \text { when } \\
\text { amikacin was discontinued. } \\
\text { Antibiotics discontinued } 2 \\
\text { months after valve surgery. }\end{array}$ & Cure. \\
\hline $\begin{array}{l}\text { Mishra et al. } \\
\text { (2015) }\end{array}$ & 53/M, India & Coronary angiogram & Aortic & Blood & $\begin{array}{l}\text { Five different antibiotics } \\
\text { administered. No surgery. }\end{array}$ & Expired. \\
\hline $\begin{array}{l}\text { Rodge et al. } \\
\text { (2017) }\end{array}$ & $61 / F$, India & $\begin{array}{l}\text { PICC, chemotherapy, } \\
\text { Non-Hodgkin's } \\
\text { lymphoma }\end{array}$ & Tricuspid & Blood, valve & $\begin{array}{l}\text { IV amikacin, linezolid, } \\
\text { moxifloxacin and } \\
\text { clarithromycin. TVR done. }\end{array}$ & Expired. \\
\hline
\end{tabular}

$\overline{\mathrm{AFB}}=$ acid fast bacilli, TVR $=$ tricuspid valve replacement, $\mathrm{PICC}=$ peripherally inserted central catheter, MVR: mitral valve replacement 
Treatment regimens for $M$. Abscessus endocarditis is not clear due to lack of randomized controlled trials. The regimens used in the past have varied, but most have used three or more antibiotics. (El Helou et al., 2013) suggested the use at least 2 active antimicrobial agents to treat $M$ abscessus bacteremia (El Helou et al., 2013). A minimum of 4 months of combination antibiotic therapy is recommended for treatment of serious infection due to $M$ abscessus (Griffith et al., 2007). We used three agents throughout the course of six weeks. Previous reports that demonstrated cure of $M$. abscessus endocarditis mention use of more than three different antibiotics (Huth et al., 2015) along with surgical intervention. In our patient, we wanted patient to receive a few more days of antibiotics before undergoing valve surgery as we feared bacterial seeding in a new valve. However, she improved clinically and decision was made not to perform surgery. Haworth et al. (2017) recommended at least 4 weeks of combination antibiotic therapy for treatment of pulmonary $M$ abscessus infection and suggested to consider duration of intravenous treatment based on the severity of infection, treatment response and tolerance of the regimen.

Although there is no consensus in terms of combination therapy, we suggest considering 3 or more agents, if tolerated, to eradicate the infection. Due to lack of data, we are unable to recommend a short course of antibiotic therapy. Due to the challenges associated with timely diagnosis, treatment and substance abuse management, these patients often pose an economic burden to our healthcare system. This case opens a debate, if in a selected group of patients, a short course of combination antibiotic therapy is enough to obtain cure. This would need further analysis.

\section{Acknowledgement}

We are highly grateful to Dr Kevin Winthrop for providing valuable advice managing the patient.

\section{Author's Contributions}

Rabindra Ghimire: Treated the patient, collected and analyzed the data, wrote the draft and revised the final draft of the manuscript.

Dora Lebron: Treated the patient, wrote the first draft and reviewed the final manuscript.

William Matthew Wooten: Submitted the abstract form in the ID week 2019 and reviewed the final manuscript.

Niki Tyler Winters: Wrote the first draft, collected imaging findings, and reviewed the final manuscript.

John M Cahill: Reviewed the imaging findings, treated patient and reviewed the final manuscript.

Alicia Lagasca, Alexandra Stang and Paul Cook: treated the patient and reviewed the final manuscript.

All authors have read and approved the contents of this manuscript.

\section{Ethics}

This article is original and contains unpublished material. The corresponding author confirms that all of the other authors have read and approved the manuscript and no ethical issues involved.

\section{Disclosures}

Authors declare that the abstract of this case was presented as a poster presentation in ID Week 2019 and had received a travel grant from IDSA. There is no other financial disclosure to be made.

\section{References}

Al-Benwan, K., S. Ahmad, E. Mokaddas, M. Johny and M.M. Kapoor, 2010. Diagnosis of endocarditis caused by Mycobacterium abscessus. Annals Saudi Med., 30: 408-411.

DOI: 10.4103/0256-4947.67086

Baker, A.W., S.S. Lewis, B.D. Alexander, L.F. Chen and R.J. Jr Wallace et al., 2007. Two-phase hospital-associated outbreak of Mycobacterium abscessus: Investigation and mitigation. Clin. Infect. Dis., 7: 902-911. DOI: 10.1093/cid/ciw877

Brown-Elliott, B.A. and R.J. Wallace, 2002. Clinical and taxonomic status of pathogenic nonpigmented or late-pigmenting rapidly growing mycobacteria. Clin. Microbiol. Rev., 15: 716-746. DOI: $10.1128 / \mathrm{cmr} .15 .4 .716-746.2002$

Bush, L.M., A. Paturi, A.F. Tower, F. Chaparro-Rojas and M.T. Perez, 2011. Mycobacterium abscessus prosthetic valve endocarditis. Infect Dis. Clin. Pract., 19: 210-212.

DOI: $10.1097 /$ ipc.0b013e3181eafc05

CDC, 2010. Mycobacterium abscessus in healthcare settings.

Corrales-Medina, V., S. Symes, M. Valdivia-Arenas and C. Boulanger, 2006. Localized Mycobacterium avium complex infection of vertebral and paravertebral structures in an HIV patient on highly active antiretroviral therapy. Southern Med. J., 99: 174-177. DOI: 10.1097/01.smj.0000198645.36984.9c

El Helou, G., G.M Viola, R. Hachem and X.Y Han, 2013. Raad II. Rapidly growing mycobacterial bloodstream infections. Lancet Infect. Dis., 13: 166-174. DOI: 10.1016/s1473-3099(12)70316-x

Fangous, M.S., F. Mougari, S. Gouriou, E. Calvez and L. Raskine et al., 2014. Classification algorithm for subspecies identification within the Mycobacterium abscessus species, based on matrix-assisted laser desorption ionization-time of flight mass spectrometry. J. Clin. Microbiol., 52: 3362-3369. DOI: $10.1128 / \mathrm{jcm} .00788-14$ 
Garcia, D.C., R. Nascimento, V. Soto and C.E. Mendoza, 2014. A rare native mitral valve endocarditis successfully treated after surgical correction. Case Reports.

Griffith, D.E., T. Aksamit, B.A. Brown-Elliott, A. Catanzaro and C. Daley et al., 2007. An official ATS/IDSA statement: Diagnosis, treatment and prevention of nontuberculous mycobacterial diseases. Am. J. Respiratory Criti. Care Med., 175: 367-416. DOI: 10.1164/rccm.200604-571st

Haworth, C.S., J. Banks, T. Capstick, A.J. Fisher and T. Gorsuch et al., 2017. British thoracic society guidelines for the management of NonTuberculous Mycobacterial Pulmonary Disease (NTM-PD). Thorax, 72: 1-64.

DOI: 10.1136/thoraxjnl-2017-210927

Huang, Y.C., M.F. Liu, G.H. Shen, C.F. Lin and C.C. Kao et al., 2010. Clinical outcome of mycobacterium abscessus infection and antimicrobial susceptibility testing. J. Microbiol. Immunol. Infect., 43: 401-406.

DOI: $10.1016 / \mathrm{s} 1684-1182(10) 60063-1$

Hussain, S.T., J. Witten, N.K. Shrestha, E.H. Blackstone and G.B. Pettersson, 2017. Tricuspid valve endocarditis. Annals Cardiothoracic Surgery, 6: 255-261.

DOI: $10.21037 /$ acs.2017.03.09

Huth, R.G., E. Douglass, K. Mondy, S. Vasireddy and R.J. Wallace, 2015. Treatment of Mycobacterium abscessus subsp. Massiliense tricuspid valve endocarditis. Emerg. Infect. Dis., 21: 535-537.

DOI: $10.3201 /$ eid2103.140577

Liebeskind, D.S., N. Ostrzega, C.G. Wasterlain and E.A. Buttner, 2001. Neurologic manifestations of disseminated infection with Mycobacterium abscessus. Neurology, 56: 810-813.

DOI: $10.1212 / \mathrm{wnl} .56 .6 .810$

Mishra, V., J. Sorabjee and S. Mahajan, 2015. Mycobacterium abscessus: Causing fatal endocarditis after cardiac catheterization. J. Postgraduate Med., 61: 131-133.

DOI: $10.4103 / 0022-3859.150898$

Redelman $\square$ Sidi, G. and K.A. Sepkowitz, 2010. Rapidly growing mycobacteria infection in patients with cancer. Clin. Infect. Dis., 51: 422-434.

DOI: $10.1086 / 655140$

Richey, L., J. Bahadorani and D. Mushatt, 2013. Endovascular Mycobacterium abscessus infection in a heart transplant recipient: A case report and review of the literature. Tran. Infect. Dis., 15: 208-213. DOI: $10.1111 /$ tid. 12024
Rodge, G., V. Nagvekar, D. Jhala and A. George, 2017. Mycobacterium abscessus causing native valve endocarditis due to peripherally inserted central catheter line. J. Clin. Tuberculosis Mycobacterial Dis., 9: 19-20. DOI: 10.1016/j.jctube.2017.09.001

Sfeir, M., M. Walsh, R. Rosa, L. Aragon and S.Y. Liu et al., 2018. Mycobacterium abscessus complex infections: A retrospective cohort study. Open Forum Infect. Dis., 5: 1-9. DOI: $10.1093 /$ ofid/ofy022

Song, X.Y., S. Li, J. Cao, K. Xu and H. Huang et al., 2016. Cardiac septic pulmonary embolism. Medicine, 95: 1-6. DOI: $10.1097 / \mathrm{md} .0000000000003846$

Tsai, W.C., H.C. Hsieh, H.M. Su, P.L. Lu and T.H. Lin et al., 2008. Mycobacterium abscessus endocarditis: A case report and literature review. Kaohsiung J. Med. Sci., 24: 481-486.

DOI: $10.1016 / \mathrm{s} 1607-551 x(09) 70005-1$

Williamson, J.C., T.A Miano, M.R Morgan and E.L. Palavecino, 2009. Fatal Mycobacterium abscessus endocarditis misidentified as Corynebacterium spp. Scandinavian J. Infect. Dis., 42: 222-224. DOI: $10.3109 / 00365540903384158$

Yuan, S.M., 2015. Mycobacterial endocarditis: A comprehensive review. Br. J. Cardiovascular Surgery, 3: 93-109. DOI: $10.5935 / 1678-9741.20140113$

Zambrano, M.M. and R. Kolter, 2005. Mycobacterial biofilms: A greasy way to hold it together. Cell, 123: 762-764. DOI: 10.1016/j.cell.2005.11.011

Zhang, Y., M. Rajagopalan, B.A. Brown and R.J. Jr. Wallace, 1997. Randomly amplified polymorphic DNA PCR for comparison of Mycobacterium abscessus strains from nosocomial outbreaks. J. Clin. Microbiol., 35: 3132-3139. DOI: 10.1128/JCM.35.12.3132-3139.1997 